\title{
Correction to: Role of mitochondria and cardiolipins in growth inhibition of breast cancer cells by retinoic acid
}

Mineko Terao ${ }^{1 \dagger}$, Laura Goracci ${ }^{2,3+}{ }^{3}$, Valentina Celestini ${ }^{1+}$, Mami Kurosaki ${ }^{1}$, Marco Bolis ${ }^{1}$, Alessandra Di Veroli ${ }^{2}$, Arianna Vallerga ${ }^{1}$, Maddalena Fratellii ${ }^{1}$, Monica Lupi ${ }^{4}$, Alessandro Corbelli ${ }^{5}$, Fabio Fiordaliso ${ }^{5}$, Maurizio Gianni ${ }^{1}$, Gabriela Paroni ${ }^{1}$, Adriana Zanetti ${ }^{1}$, Gabriele Cruciani ${ }^{2,3}$ and Enrico Garattini ${ }^{{ }^{*}}$

\section{Correction to: J Exp Clin Cancer Res (2019) 38:436 https://doi.org/10.1186/s13046-019-1438-y}

In the original publication of this article [1], the images of Figs. 4 and 5 were exchanged and the legends of the two figures did not correspond due to a typesetting error.

The publisher sincerely apologizes for the inconvenience caused to the readers.

The original article has been corrected.

\begin{abstract}
Author details
'Laboratory of Molecular Biology, Istituto di Ricerche Farmacologiche Mario Negri IRCCS, via La Masa 19, 20156 Milan, Italy. ${ }^{2}$ Department of Chemistry, Biology and Biotechnology, University of Perugia, via Elce di Sotto 8, 06123 Perugia, Italy. ${ }^{3}$ Consortium for Computational Molecular and Materials Sciences (CMS), via Elce di Sotto 8, 06123 Perugia, Italy. ${ }^{4}$ Department of Oncology, Istituto di Ricerche Farmacologiche Mario Negri IRCCS, via La Masa 19, 20156 Milan, Italy. ${ }^{5}$ Department of Cardiovascular Research, Istituto di Ricerche Farmacologiche Mario Negri IRCCS, via La Masa 19, 20156 Milan, Italy.
\end{abstract}

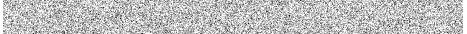

\section{Reference}

1. Terao M, et al. Role of mitochondria and cardiolipins in growth inhibition of breast cancer cells by retinoic acid. J Exp Clin Cancer Res. 2019;38:436.

\footnotetext{
* Correspondence: enrico.garattini@marionegri.it

The original article can be found online at https://doi.org/10.1186/s13046019-1438-y

${ }^{\dagger}$ Mineko Terao, Laura Goracci and Valentina Celestini contributed equally to this work.

'Laboratory of Molecular Biology, Istituto di Ricerche Farmacologiche Mario Negri IRCCS, via La Masa 19, 20156 Milan, Italy

Full list of author information is available at the end of the article
}

(c) The Author(s). 2019 Open Access This article is distributed under the terms of the Creative Commons Attribution 4.0 International License (http://creativecommons.org/licenses/by/4.0/), which permits unrestricted use, distribution, and reproduction in any medium, provided you give appropriate credit to the original author(s) and the source, provide a link to the Creative Commons license, and indicate if changes were made. The Creative Commons Public Domain Dedication waiver (http://creativecommons.org/publicdomain/zero/1.0/) applies to the data made available in this article, unless otherwise stated. 


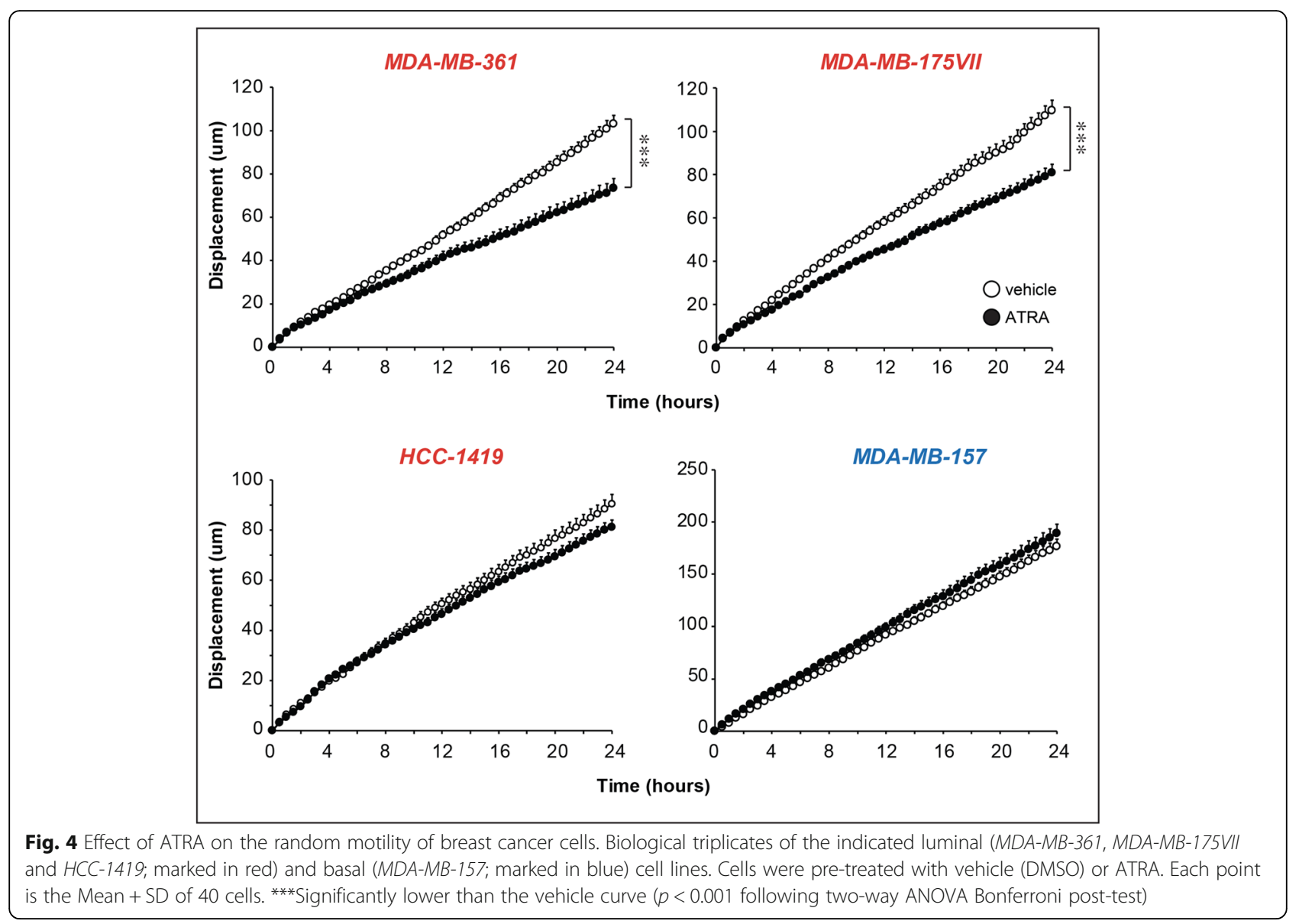




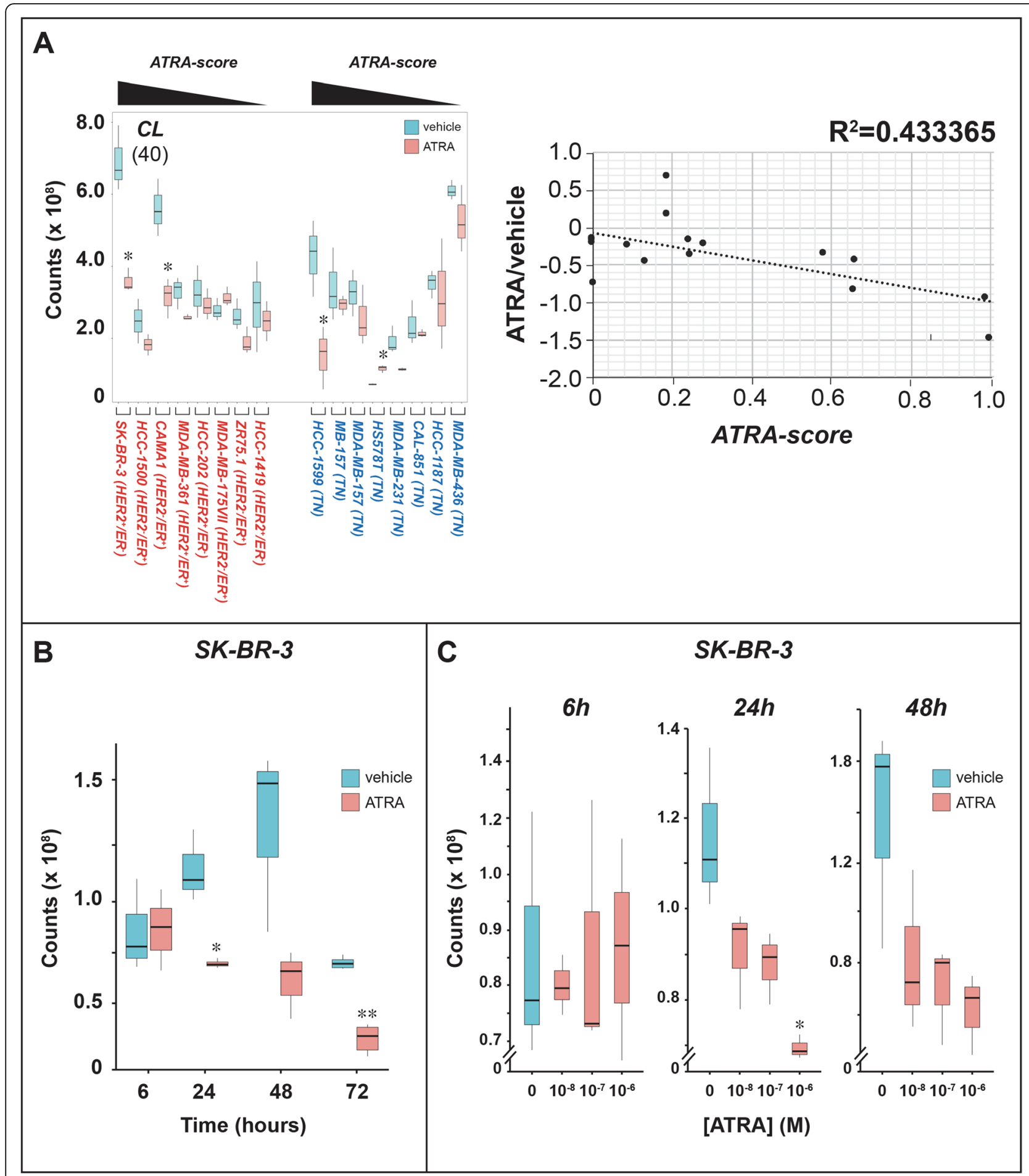

Fig. 5 (See legend on next page.) 
(See figure on previous page.)

Fig. 5 ATRA effects on the levels of cardiolipins. a Biological triplicates of the indicated breast cancer cells were treated with vehicle (DMSO) or ATRA $\left(10^{-6} \mathrm{M}\right)$ for $48 \mathrm{~h}$. Left: The box plots show the median \pm SD levels of cardiolipins (CLs). The number of different $C L$ molecules identified by mass-spectrometry is indicated in parenthesis. Luminal cell-lines are marked in red and basal cell-lines are marked in blue. The luminal and basal cell-lines are ordered according to decreasing sensitivity to the anti-proliferative effect of ATRA from left to right, as indicated (decreasing ATRAscore). Right: The diagram indicates the correlations between the ATRA/DMSO ratio of the mean values calculated for CLs in each cell-line and the corresponding ATRA-score. $\mathbf{b}$ Biological triplicates of SK-BR-3 cells were treated with vehicle (DMSO) or ATRA $\left(10^{-6} \mathrm{M}\right)$ for the indicated amounts of time. The box plot shows the median \pm SD levels of cardiolipins (CLs). c Biological triplicates of SK-BR-3 cells were treated with vehicle (DMSO) or the indicated concentrations of ATRA for $48 \mathrm{~h}$. The box plot shows the median \pm SD levels of cardiolipins (CLs). *Significantly different $(p<0.05)$ from the corresponding vehicle treated control using the Student's t-test. * Significantly different $(p<0.01)$ from the corresponding vehicle treated control using the Student's t-test 